

Read, B. (2016) Gender and higher education. In: Shin, J. C. and Teixeira, P. (eds.) Encyclopedia of International Higher Education Systems and Institutions. Springer: Berlin. ISBN 9789401795531 (doi:10.1007/978-94-017-9553-1_44-1).

There may be differences between this version and the published version. You are advised to consult the publisher's version if you wish to cite from it.

http://eprints.gla.ac.uk/135737/

Deposited on: 6 February 2020

Enlighten - Research publications by members of the University of Glasgow http://eprints.gla.ac.uk 


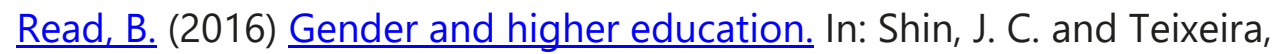

P. (eds.) Encyclopedia of International Higher Education Systems and

Institutions. Springer: Berlin. ISBN 9789401795531 (doi: 10.1007/978-94-017-

9553-1 44-1)

\section{Gender and Higher Education}

Research relating to gender in Higher Education has a wide range of foci, ranging from issues of student participation and achievement; curriculum and pedagogy; and the recruitment/promotion of academic staff; to engagements with the 'genderedness' of academic culture/ institutional life, constructions of the 'ideal' or typical student or academic, and the ways in which such constructions connect to wider social patterns of gendered inequality. Most research in this area is explicitly feminist in approach, and the development of the field has reflected major developments/debates in feminist social research more broadly, including the critiques of 'second wave' feminism by women of colour; a stress on intersectionality, and the influence of the 'postmodern turn', queer theory, and humanist/material approaches.

Key overarching debates in the field include the gendered impacts of globalization, the increased casualization of labour, the rising dominance of neoliberalist managerialism and the associated framing of what is seen as valuable in terms of academic work and knowledge (see e.g. Kenway and Langmead, 1998; Morley, 1999; Brooks and McKinnon, 2001; Currie et al., 2002; Davies, 2003). Researchers have explored the gendered effects and implications of these, noting that whilst some aspects of managerialist culture in HE can arguably benefit gender equality (notably increased levels of transparency and accountability in academic appointments and promotions), the increased pressure to 'perform' in the academic 'marketplace' has contributed to rising levels of stress and anxiety amongst academics, with notable class, 'raced' and gendered patternings (see e.g. Acker and Armenti, 2004; Hey, 2011)

In relation to student access to HE, women's access has improved considerably across many countries in the world. In most 'developed' countries and those in transition, women now form a numerical majority on university campuses, although they remain a minority in many countries in sub-Saharan Africa, South, West and East Asia (see e.g. Leathwood and Read, 2009, Malik and Courtney 2011). Especially in the global North, women's rising levels of success in achievement as well as participation at university has led to a media/popular concern that these trends are problematic and the academy has become - or is in danger of becoming - 'feminised'. Historians of higher education have provided an important historical perspective to such anxieties, exploring how women's entry into HE in the $19^{\text {th }}$ early $20^{\text {th }}$ centuries were often accompanied by fears of loss of status of the institutions/disciplines they were entering, and a fear of the 'emasculation' of men (see Dyhouse, 2006). Feminist educationalists have pinpointed similar concerns in contemporary media/popular discourse, in particular the fear a) that women's success means that men are inevitably 'losing out' and b) that higher education is (or must be) becoming less elite and prestigious. 
These arguments have been widely countered by feminists, who argue firstly that there remain considerable gender imbalances in terms of participation and success in many countries and type of institution across the world (see Leathwood and Read, 2009). For example, Pereira (2007) argues that issues of prejudice and sexual harassment contribute to high rates of dropout for women students in Nigeria (between a third and two thirds in some disciplines/institutions). Importantly, issues relating to sexual harassment and violence against women on campus remain a pressing concern in many countries (see e.g. Phipps and Smith, 2012).

Patterns of participation and success also vary hugely by discipline (see e.g. Torres, 2012 in relation to STEM). Furthermore, simplistic binary comparisons between men and women students masks considerably higher disparities of access and achievement in relation to social class, 'race'/ethnicity, dis/ability, sexuality and age (Mirza, 2005; Moreau and Leathwood, 2006) with intersectional studies on non-participant, student and staff experience an important strand of research (see e.g. Archer and Hutchings 2000; Cole and Ahmadi, 2003; David et al., 2003; Quinn, 2003; Reay et al., 2005, 2010; Cortes Santiago et al., 2010; Taylor and Falconer, 2016).

Such research counters the 'feminization' argument through an exploration of the continued ways in which gender infuses academic cultural practices in the academy. For example, researchers have explored gendered cultural issues underpinning continued inequities in levels of senior academic appointments and conceptions of leadership (e.g. Blackmore, 2014; Morley 2014), in applications for research funding (see e.g. Wenneras and Wold, 1997; Leberman et al., 2016); and practices of speaking, writing and 'presentation of self (Grant and Knowles, 2000; Francis et al., 2001; Jackson and Dempster, 2009). Finally, a notable area of research involves the exploration of gendered discourses in knowledge, curriculum and pedagogy (e.g. Burke and Crozier, 2014), including the enormous possibilities and institutional challenge of Women's Studies as a subject, and the continued impact of academic feminism across the disciplines (Coate, 2006; David, 2014).

\section{References}

Acker, Sandra and Carmen Armenti. 2004. Sleepless in Academia. Gender and Education 16, 1: 3-24.

Archer, Louise and Merryn Hutchings. 2000. 'Bettering Yourself'? Discourses of risk, cost and benefit in ethnically diverse, young working-class non-participants' constructions of higher education. British Journal of Sociology of Education 21, 4: 555-574.

Blackmore, Jill. 2014. 'Wasting talent'? Gender and the problematics of academic disenchantment and disengagement with leadership. Higher Education Research and Development, 33, 1: 86-99.

Brooks, Ann, and Alison Mackinnon. 2001. Gender and the Restructured University. Basingstoke: SRHE and Open University Press. 
Burke, Penny J., and Gill Crozier. 2014. Higher Education Pedagogies: Gendered formations, mis/recognition and emotion. Journal of Research in Gender Studies 4, 2: $52-67$.

Kelly Coate. 2006. Imagining Women in the Curriculum: the transgressive impossibility of Women's Studies. Studies in Higher Education, 31, 4: 407-421.

Cole, Darnell, and Shafiqa Ahmadi. 2003. Perspectives and Experiences of Muslim Women Who Veil on College Campuses. Journal of College Student Development 44, 1: 47-66.

Ileana Cortes Santiago, Nastaran Karimi and Zaira R. Arvelo Alicea. 2016.

Neoliberalism and Higher Education: a collective autoethnography of Brown Women

Teaching Assistants. Gender and Education, DOI: 10.1080/09540253.2016.1197383

Currie, Jan, Bev Thiele, and Patricia Harris. 2002. Gendered Universities in Global Economies: Powers, Careers and Sacrifices. Lanham, Maryland: Lexington.

David, Miriam. 2014. Feminism, Gender and Universities: Politics, Passion and Pedagogies. London, Routledge.

Davies, Bronwyn. 2003. Death to Critique and Dissent? The Policies and Practices of New Managerialism and of 'Evidence-based Practice'. Gender and Education 15, 1: 91-103.

Dyhouse, Carole. 2006. Students: A Gendered History. London: Routledge.

Francis, Becky, Jocelyn Robson and Barbara Read. 2001. An Analysis of Undergraduate Writing Styles in the Context of Gender and Achievement. Studies in Higher Education 26, 3: 313-326.

Grant, Barbara and Sally Knowles. 2000. Flights of Imagination: Academic women be(com)ing writers. International Journal for Academic Development 5, 1: 6-19.

Hey, Valerie. 2011. Affective Asymmetries: Academics, austerity and the mis/recognition of emotion. Contemporary Social Science: Journal of the Academy of Social Sciences 6, 2: 207-222.

Jackson, Carolyn and Steven Dempster. 2009. 'I Sat Back on my Computer ... With a Bottle of Whisky Next to Me': Constructing 'cool' masculinity through 'effortless' achievement in secondary and higher education. Journal of Gender Studies 18, 4: 341-356.

Kenway, Jane and Langmead, Diana. 1998. Governmentality, the 'Now' University and the Future of Knowledge Work. Australian Universities Review 41, 2: 28-32.

Leathwood, Carole, and Barbara Read. 2009. Gender and the Changing Face of Higher Education: a Feminized Future? Basingstoke: SRHE and Open University Press. 
Leberman, Sarah I., Brigit Eames and Shirley Barnett. 2016. 'Unless You Are Collaborating with a Big Name Successful Professor, You are Unlikely to Receive Funding'. Gender and Education 28, 5: 644-661.

Leonard, Diana. 2001. A Woman's Guide to Doctoral Studies. Independence, KY: Taylor and Francis.

Malik, Samina and Kathy Courtney. 2011. Higher Education and Women's Empowerment in Pakistan. Gender and Education 23, 1: 29-45.

Mirza, Heidi Safia. 2005. Race, Gender and Educational Desire. London: Routledge.

Moreau, Marie-Pierre and Carole Leathwood. 2006. Balancing Paid Work and Studies: Working (-class) students in higher education. Studies in Higher Education 31, 1: 23-42.

Morley, Louise. 1999. Organizing Feminisms: The Micropolitics of the Academy. Basingstoke and London: Macmillan.

Morley, Louise. 2014. Lost Leaders: Women in the Global Academy. Higher Education Research and Development 33, 1: 114-128.

Pereira, Charmaine. 2007. Gender in the Making of the Nigerian University System. Ibadan/Oxford: Heinemann Educational Books (Nigeria) and James Currey.

Phipps, Alison and Smith, Geraldine. 2012. Violence against Women Students in the UK: Time to take action. Gender and Education 24, 4: 357-373.

Quinn, Jocey. 2003. Powerful Subjects: Are women really taking over the university? Stoke on Trent: Trentham.

Reay, Diane, Miriam E. David and Stephen J. Ball. 2005. Degrees of Choice: Class, Race, Gender and Higher Education. Stoke-on-Trent: Trentham.

Reay, Diane, Gill Crozier and John Clayton. 2010. 'Fitting In' or 'Standing Out': Working-class students in Higher Education. British Educational Research Journal $36,1: 107-124$.

Taylor, Yvette, and Emily Falconer. 2016. Negotiating Queer and Religious Identities in Higher Education : Queering 'Progression' in the 'University Experience'. British Journal of Sociology of Education (forthcoming in press).

Torres, Lisette E. 2012. Lost in the Numbers: Gender Equity Discourse and Women of Color in Science, Technology, Engineering and Mathematics (STEM). International Journal of Science in Society 3, 4. 33-45.

Wenneras, Christine, and Agnes Wold. 1997. Nepotism and Sexism in Peer-Review. Nature 387, 6631: 341-343. 
